\title{
Production of Functional High-protein Beverage Fermented with Lactic Acid Bacteria Isolated from Korean Traditional Fermented Food
}

\author{
Young-Hee Cho, II-Seung Shin, Sung-Moon Hong, and Cheol-Hyun Kim* \\ Department of Animal Resource \& Science, Dankook University, Cheonan 330-714, Korea
}

\begin{abstract}
The aim of this study was to manufacture functional high protein fermented beverage, using whey protein concentrate (WPC) and Lactobacillus plantarum DK211 isolated from kimchi, and to evaluate the physicochemical, functional, and sensory properties of the resulting product. The fermented whey beverage (FWB) was formulated with whey protein concentrate 80 (WPC 80), skim milk powder, and sucrose; and fermented with Lactobacillus plantarum DK211 as single, or mixed with Lactococcus lactis R704, a commercial starter culture. The $\mathrm{pH}$, titratable acidity, and viable cell counts during fermentation and storage were evaluated. It was found that the mixed culture showed faster acid development than the single culture. The resulting FWB had high protein ( $9 \%)$ and low fat content $(0.2 \%)$. Increased viscosity, and antioxidant and antimicrobial activity were observed after fermentation. A viable cell count of $10^{9} \mathrm{CFU} /$ $\mathrm{mL}$ in FWB was achieved within $10 \mathrm{~h}$ fermentation, and it remained throughout storage at $15^{\circ} \mathrm{C}$ for $28 \mathrm{~d}$. Sensory analysis was also conducted, and compared to that of a commercial protein drink. The sensory scores of FWB were similar to those of the commercial protein drink in most attributes, except sourness. The sourness was highly related with the high lactic acid content produced during fermentation. The results showed that WPC and vegetable origin lactic acid bacteria isolated from kimchi might be used for the development of a high protein fermented beverage, with improved functionality and organoleptic properties.
\end{abstract}

Key words: whey protein, fermented beverage, Lactobacillus plantarum, antioxidant activity, sensory analysis

(Received 2014.11.6/Revised 2015.1.16/Accepted 2015.1.23)

\section{Introduction}

Probiotic bacteria has been shown to have effects in enhancement of the immune system, and in prevention of gut, vaginal, and urogenital infections, diarrhea, and gastritis, by inhibiting enteric and foodborne microbial pathogens (Walsh et al., 2010). Consumers' interest in functional foods containing probiotic bacteria and prebiotics has created a huge market, and their market share is still expanding (Rathore et al., 2012; Walsh et al., 2010). The consumer request for food with nutritional benefits is also quickly improved, which has generated the manufacture of various value-added dairy products (Shiby et al., 2013). Recently, the sales of ready-to-drink (RTD) protein drinks have been increased through mainstream supermarket distribution.

The value of proteins as an essential source of amino acids is well documented, but recently it has been recog-

\footnotetext{
*Corresponding author: Cheol-Hyun Kim, Department of Animal Resource \& Science, Dankook University, Cheonan 330714, Korea. Tel: +82-41-550-3656, Fax: +82-41-622-2207, Email: hichkim@dankook.ac.kr
}

nized that dietary proteins exert many other functionalities in vivo, by means of biologically active peptides. Such peptides are inactive within the sequence of the parent protein, and can be released by digestive enzymes during gastrointestinal transit, or by fermentation or ripening during food processing (Korhonen, 2009). In particular, milk proteins are regarded as a source of energy and of essential amino acids, which are needed for growth and maintenance of physiological functions (Unal and Akalm, 2012).

Whey protein, a by-product recognized as a valuable food ingredient with important nutritional and functional properties, is gaining acceptance as a functional food ingredient. Commercial whey proteins are considered a GRAS (Generally Recognized As Safe) substance for food product applications (Sinha et al., 2007). A wide variety of whey ingredients are available for use in the manufacture of yogurt and fermented beverages, including sweet whey powder (SWP), whey protein concentrate (WPC), whey protein isolate (WPI) and specialized WPCs (Hugunin, 2008). Whey proteins possess high biological value, and are superior to other proteins, such as those of egg, soy and caseins of milk, mainly due to their high content of branched essential amino acids (Pescuma et al., 2010; 
Shiby et al., 2013).

Whey-based lactic beverages represent an emerging segment of non-conventional dairy products that require sensory, physical, and chemical characterization for quality control and product development (Almeida et al., 2009). However, consumer acceptance of these health drinks depends on the development of nutritional beverages that maintain their desirable appearance, texture, and flavor characteristics during storage and consumption (Shiby et al., 2013). Numerous formulations of liquid products based on whey proteins have been developed to improve their characteristics (Almeida et al., 2009; Athanasiadis et al., 2004; Djurić et al., 2004; Pescuma et al., 2010: Shiby et al., 2013). However, the protein contents of products in their studies are less than $5 \%$. Whey proteins that are not modified to have more heat stability will not be stable as the sole ingredient at levels above $3 \%$ protein, that is, they will gel or precipitate under high heat treatment (Rittmanic, 2008). A typical yogurt and Greek yogurt provides on average 3 and $6.7 \mathrm{~g}$ protein $/ 100 \mathrm{~g}$ serving, respectively. The protein contents in commercial protein drinks or shakes are mostly between 6 and $10 \%$.

The aim of this study was to formulate a novel functional fermented whey beverage containing high protein content, by using whey protein, and lactic acid bacteria isolated from Korean traditional fermented foods. However, a potential issue with culture is the use of vegetableorigin probiotic in a milk-based product containing high protein content; consequently, this probiotic would be potentially unsuited to growth in milk-based product. Moreover, the incubation time is highly related with the production capacity in plant. The reduction in fermentation time could increase the production capacity of plant, and significantly reduce production costs (Hugunin, 2008). A commercial strain, Lactococcus lactis R704 was selected for mixture use with vegetable-origin lactic acid bacteria isolated from kimchi in previous study, as it is extensively used for the industrial production of fermented milk, cheese, and yogurt (Khalid et al., 2011).

Hence, this study was conducted (1) to optimize the conditions to develop a fermented whey beverage with acceptable organoleptic properties, (2) to determine functional properties, such as antioxidant activity and antimicrobial activity, and (3) to assess the shelf life of the product.

\section{Materials and Methods}

\section{Strains and materials}

The strain, Lactobacillus plantarum DKL 121 was iso-
Table 1. The composition of whey protein concentrate (WPC) and skim milk powder (SMP)

\begin{tabular}{ccc}
\hline \hline & \multicolumn{2}{c}{ Concentration (g/100 g powder) } \\
\cline { 2 - 3 } & WPC & SMP \\
\hline Protein & 80 & 35 \\
Fat & 0.1 & 52 \\
Lactose & 6.5 & 1.0 \\
\hline
\end{tabular}

lated from kimchi samples, and maintained in glycerol stocks at $-20^{\circ} \mathrm{C}$. Four commercial strains: Lactobacillus helveticus (LH 166, Culture System Inc, USA), Lactobacillus plantarum (LP-5, Culture System Inc, USA), Streptococcus thermophiles (ST-Body 1, Christian Hansen, Denmark), and Lactococcus lactis (L. lactis R704, Christian Hansen, Denmark) were used in this study depending on the purpose of use.

Whey protein concentrate (WPC 80) and skim milk were purchased from Sung Poon Co. (Korea) and Seoul milk (Korea), respectively. Table 1 shows the compositions of these dairy ingredients. Sucrose was obtained from CJ Co. (Korea). All other chemicals and reagents used were of analytical grade, and were purchased from Sigma-Aldrich (USA).

\section{Fermentation condition}

Samples were withdrawn every $2 \mathrm{~h}$ during $24 \mathrm{~h}$ incubation, for the measurements of $\mathrm{pH}$, titratable acidity, and viable cell counts. Bacterial growth was observed with enumerated viable colony at the MRS agar plates incubated at $37^{\circ} \mathrm{C}$ for $48 \mathrm{~h}$.

\section{Manufacture of fermented whey beverage}

Fermented whey beverage was prepared, using $11 \%(\mathrm{w} /$ v) WPC $80,2 \%(\mathrm{w} / \mathrm{v})$ skim milk powder, and $10.3 \%$ sugar. Each strain was subcultured triplicate in MRS broth at $37^{\circ} \mathrm{C}$. All dry ingredients were dissolved in sterile water, and homogenized with a homomixer (IKA, Japan) at $10,000 \mathrm{rpm}$. This mixture was then pasteurized at $70^{\circ} \mathrm{C}$ for $30 \mathrm{~min}$, cooled to about $40^{\circ} \mathrm{C}$, inoculated culture at a rate of $20 \mathrm{~mL} / \mathrm{L}\left(10^{8} \mathrm{CFU} / \mathrm{mL}\right)$, and fermented at $37^{\circ} \mathrm{C}$ for $10 \mathrm{~h}$. The resulting FWB was distributed in sterile glass bottles, and stored at 4,10 , and $15^{\circ} \mathrm{C}$ for $28 \mathrm{~d}$. Viable cell count, $\mathrm{pH}$, and titratable acidity were measured after $0,7,14,21$, and $28 \mathrm{~d}$ of storage. The FWBs containing commercial strains (LH 166 or ST-Body 1) were also prepared as above, except for the fermentation time. The fermentation time of FWB with Lactobacillus helveticus LH 166 and that with ST-body were $13 \mathrm{~h}$ and $14.5 \mathrm{~h}$, respectively. 


\section{Assay for proteolytic activity}

Proteolytic activity was assessed by an agar diffusion method. Milk agar plates containing $1.6 \%(\mathrm{w} / \mathrm{v})$ skim milk and $1.5 \%(\mathrm{w} / \mathrm{v})$ agar were prepared. Three hundred $\mu \mathrm{L}$ of each strain at a final concentration of $10^{8} \mathrm{CFU} / \mathrm{mL}$ was inoculated onto plates. After incubation at $37^{\circ} \mathrm{C}$ for $48 \mathrm{~h}$, absence of an inhibitory zone was observed. Each plate was examined for clear zones.

\section{Measurement of physical properties}

The measurement of $\mathrm{pH}$ was conducted at room temperature, using a digital $\mathrm{pH}$ meter (Orion 3 star, Thermo Scientific, Korea). Titratable acidity expressed as a percentage of lactic acid was measured by titrating $9 \mathrm{~mL}$ of the sample with $0.1 \mathrm{~N} \mathrm{NaOH}$, until the substance reached to the end point of the phenolphthalein. The viscosity was measured by a dynamic viscometer (RVDI, Brookfield, USA).

\section{Measurement of chemical analysis}

The organic acid contents were determined using highperformance liquid chromatography (HPLC), consisting of UV/visible detector (Waters 410, Waters, USA). Five mL of samples were mixed with $5 \mathrm{~mL}$ of $0.0085 \mathrm{~N} \mathrm{H}_{2} \mathrm{SO}_{4}$, and stood at room temperature for $2 \mathrm{~h}$. This mixture was centrifuged at 4,000 $\mathrm{g}$ for $10 \mathrm{~min}$, and then filtered with a syringe filter (pore size $0.22 \mu \mathrm{m}$ ). The chromatographic analysis was conducted using hydrosphere $\mathrm{C} 18$ column (4.6 $\mathrm{mm} \times 150 \mathrm{~mm}$, particle size $5 \mu \mathrm{m}$, YMC, Japan). The mobile phase used was $0.0085 \mathrm{~N} \mathrm{H}_{2} \mathrm{SO}_{4}$. The chromatographic separation of samples $(20 \mu \mathrm{L})$ was performed at a constant flow rate of $0.6 \mathrm{~mL} / \mathrm{min}$. The concentration was calculated by using the peak area obtained with standard organic acids (acetic acid and lactic acid).

\section{Measurement of DPPH radical scavenging activity}

This method is based on reduction of the free radical DPPH (1,1-diphenyl-2-picrylhydrzyl). A $0.2 \mathrm{mM} / \mathrm{L}$ DPPH radical solution in $99 \%$ ethanol was prepared. A $100 \mu \mathrm{L}$ aliquot of each sample was added to $1 \mathrm{~mL}$ of $0.2 \mathrm{mM}$ DPPH solution containing $50 \mu \mathrm{L}$ of ethanol. After gentle mixing, the solution was incubated at $37^{\circ} \mathrm{C}$ for $30 \mathrm{~min}$. The absorbance was measured at $515 \mathrm{~nm}$, using an UV spectrophotometer (X-ma 1200, Human Co., Korea). Trolox was used as a reference antioxidant, at a concentration of $0.1 \mathrm{mg} / \mathrm{mL}$. Free radical scavenging activities were calculated as

$$
\text { [(1 - (sample O.D. / blank O.D. })) \times 100]
$$

\section{Measurement of ferric reducing antioxidant power (FRAP)}

This method was used to measure the reductive power of samples. The FRAP reagent was prepared by mixing $300 \mathrm{mM}$ sodium acetate buffer (pH 3.6), $10 \mathrm{mM}$ 2,4,6tripyridyl-s-triazine (TPTZ), and $20 \mathrm{mM} \mathrm{FeCl}_{3}$ at a ratio of 10:1:1 (v/v/v). One $\mathrm{mL}$ of each sample was mixed with $100 \mu \mathrm{L}$ of trichloroacetic acid with vortexing, then centrifuged for $10 \mathrm{~min}$ at $9,300 \mathrm{~g}$. The supernatant $(40 \mu \mathrm{L})$ was mixed with $1.2 \mathrm{~mL}$ of FRAP reagent and $20 \mu \mathrm{L}$ of distilled water; and then this mixture was incubated at $37^{\circ} \mathrm{C}$ for $5 \mathrm{~min}$. The absorbance was measured at $593 \mathrm{~nm}$ using a spectrophotometer, using deionized water as the blank. Trolox was used as the positive control. The results were expressed as micromoles of $\mathrm{Fe}(\mathrm{II})$, using a linear calibration curve obtained with different concentrations of $\mathrm{FeSO}_{4}$.

\section{Antimicrobial activity assay}

Staphylococcus aureus and Salmonella enterica were used as test strains, to evaluate the antimicrobial effects of FWB samples. These strains were incubated in LB broth for $18 \mathrm{~h}$ at $37^{\circ} \mathrm{C}$, then $0.15 \mathrm{~mL}$ of cell culture was spread onto LB agar. The paper disc (diameter, $10 \mathrm{~mm}$ ) was soaked with $100 \mu \mathrm{L}$ of each FWB sample. The soaked paper discs were placed on the surface of each plate. After incubation at $37^{\circ} \mathrm{C}$ for $18 \mathrm{~h}$ under aerobic condition, each plate was examined for the clear inhibition zones around the paper disc.

\section{Sensory evaluation}

The samples were subjected to sensory evaluation. The control was a commercial protein drink, a banana-flavored processed milk fortified with milk protein concentrate (MPC). Thirty-five panelists were employed, and the members of this panel were students selected for their familiarity with yogurt products, but who received no training at all, in order to represent the average consumer. The FWB and commercial product were presented to panels in identical plastic cups labeled with random numbers, and in random order. Each panelist was asked to rate the samples for the four attributes (overall taste, flavor, offflavor, freshness, and aftertaste) using a 7-point hedonic scale (1="I dislike extremely", 7="I like extremely"). The intensities of sweetness, sourness, and off-flavor were evaluated using a 7-point "just-about-right" scale, ranging from 1="much too mild", to 7="much too strong". Statistical analysis was conducted using ANOVA, where the significant effect was found. Significance of differences 
between samples was determined on the basis of Turkey's test, at a significance level of $p<0.05$. The statistical analysis was performed using Statistica 8.0 software (StatSoft Inc., USA).

\section{Results and Discussion}

\section{Selection of culture}

In previous study, a total of 106 colonies were isolated from Kimchi samples. Of them, 60 colonies were identified as Lactobacillus species, through observation of phenotypic characters, and identification using API kit and $16 \mathrm{~S}$ rRNA gene sequencing. Further studies on acid tolerance, bile tolerance, and proteolytic activity were conducted, to select strains for commercial use as probiotics and starter culture in dairy products. It was found that $L$. plantarum DK 211 had tolerance under acid and bile conditions, as its viable cell count remained at $\mathrm{pH} 2.0$ and under $1.0 \%$ bile salt condition, after $2 \mathrm{~h}$ incubation time (data not shown). Other studies (Lee et al., 2011; Lim and Im, 2009) conducted on L. plantarum strain isolated from kimchi, also indicated that L. plantarum strain had acid and bile tolerance, compared with other species.

The proteolytic system of lactic acid bacteria is essential for their growth in milk and ripening of fermented milk products, because it leads to the liberation of peptides and amino acids, which consequently has considerable effects on the physical structure, taste, and flavor development (Beganović et al., 2013; Cho et al., 2013; Khalid and Marth, 1990). Skimmed milk agar plate assays allow principally for qualitative determinations of protease activity, as the hydrolysis zone produced on the skim milk agar could be related to the amount of protease produced by the bacteria (Vijayaraghavan and Vincent, 2013). For the determination of proteolytic activity, a zone of proteolysis was detected on the skimmed milk agar plates. As shown in Fig. 1, this strain possesses strong proteolytic activity, as it produced larger clear zones on milk agar than commercial Lactobacillus plantarum strain, LP-5. It showed similar proteolytic activity to 911 LC. The high proteolytic activity of 911LC was proven by the study of Ko et al. (2005). The proteolytic activities of all cultures studied in this study followed a timedependent pattern.

\section{Growth patterns of culture}

Whey proteins will gel or precipitate under high heat treatment, when they are used at levels above 3\% protein as the sole ingredient. Therefore, whey protein beverages

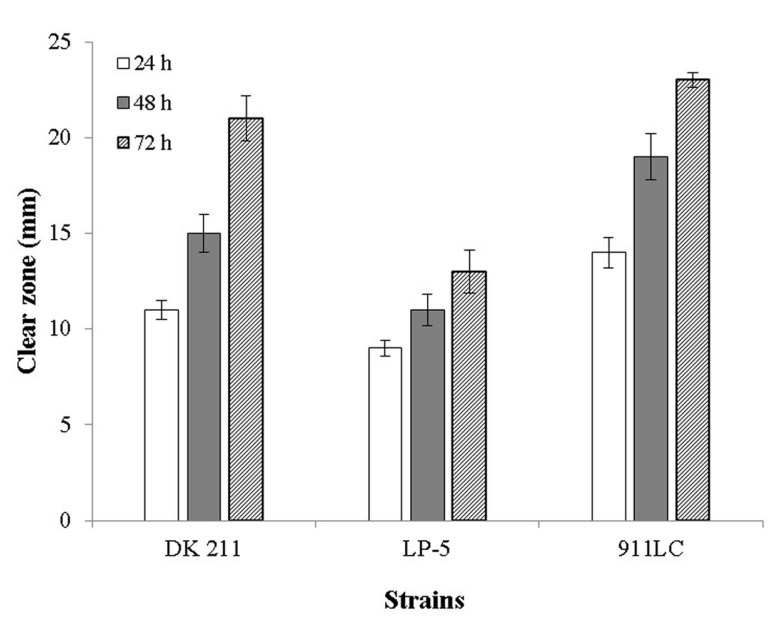

Fig. 1. Comparison of proteolytic activity of $L$. plantarum DK 211 and commercial strains; $L$. plantarum LP-5 and $L$. casei 911 LC using skim milk agar plate. The plates were incubated at $37^{\circ} \mathrm{C}$ for 24,48 and $72 \mathrm{~h}$.

are generally formulated to a $\mathrm{pH}$ of less than 4.5 , because they are subjected to a mild thermal pasteurization process (Rittmanic, 2008). The current minimum standard for yogurt manufacture is about $0.9 \%$ acidity, at a final pH between 4.2 and 4.5 (Campagne et al., 2010).

The growth kinetic of $L$. plantarum DK 211 was estimated by measuring the $\mathrm{pH}$, titratable acidity, and viable cell count during fermentation. The growth curve obtained by measuring the $\mathrm{pH}$ and titratable acidity was used to estimate at what point in time the bacteria reached to $\mathrm{pH}$ 4.5. As shown in Fig. 2, the $\mathrm{pH}$ of culture media sharply decreased, until it reached to $\mathrm{pH} 4.5$ at $18 \mathrm{~h}$ of incubation. When mixture culture of L. plantarum DK 211 and Lactococcus lactis was used, there was almost 30\% reduction

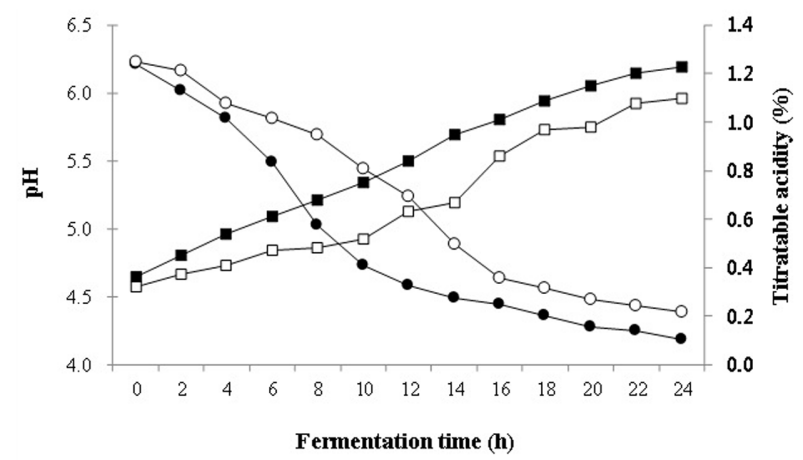

Fig. 2. Changes in pH and titratable acidity of fermented whey beverage with Lactobacillus plantarum DK 211 and mixed culture (Lactobacillus plantarum DK 211+ Lactococcus lactis R704) during fermentation. $\bullet: \mathrm{pH}$ in mixed culture, $\bigcirc: \mathrm{pH}$ in Lactobacillus plantarum DK 211 , $\square$ : titratable acidity in mixed culture, $\square$ : titratable acidity in Lactobacillus plantarum DK 211. 


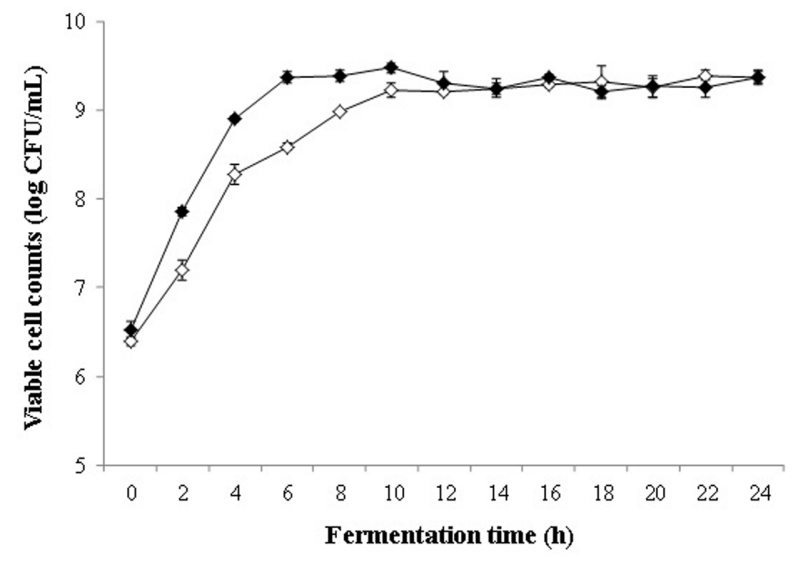

Fig. 3. Changes in viable cell counts of whey fermented beverage with Lactobacillus plantarum DK $211(\diamond)$ and mixed culture (Lactobacillus plantarum DK 211+ Lactococcus lactis R704: $\diamond)$ during fermentation.

in the incubation time required to reach $\mathrm{pH} 4.5$. Almeida et al. (2009) also observed that the bases fermented by co-culture were generally faster in reaching $\mathrm{pH} 4.5$.

High viable counts are necessary to get the desired acid production and reduction in $\mathrm{pH}$, which affect organoleptic properties of the final product and its shelf-life, and prevent product contamination (Rathore et al., 2012). During fermentation, the population of L. plantarum DK 211 rapidly increased at the beginning, and the growth reached a stationary phase after $10 \mathrm{~h}$ (Fig. 3). The viable cell counts increased from an initial value of $6.5 \mathrm{Log} \mathrm{CFU} / \mathrm{mL}$, to above $9.0 \mathrm{Log} \mathrm{CFU} / \mathrm{mL}$ at $10 \mathrm{~h}$ of incubation time. On the other hand, the population of mixed culture of $L$. plantarum DK 211 and L. lactis R704 reached above 9 Log CFU/mL at $6 \mathrm{~h}$ of incubation time. An ideal starter culture should be quick and steady in acid production (Cho et al., 2013). Campagne et al. (2010) also stated that mixing strains could affect the growth and acidification rates, which are important benefits for sanitary and economic standpoints. According to these results, mixed culture of L. plantarum DK 211 and L. lactis R704 with 10 $\mathrm{h}$ of fermentation time was selected for the preparation of FWB in the further study.
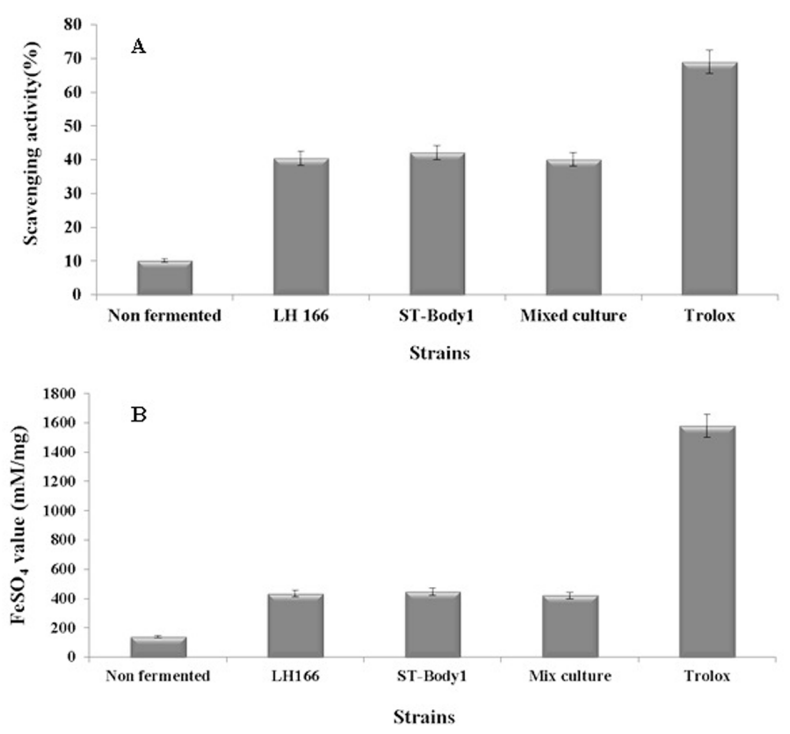

Fig. 4. Comparison in DPPH radical scavenging activity (A) and FRAP values (B) for non-fermented whey beverage, whey fermented beverage with Lactobacillus helveticus LH166, whey fermented beverage with Streptococcus thermophilus ST-Body1 and whey fermented beverage with mixed culture (Lactobacillus plantarum DK 211+ Lactococcus lactis R704), positive control: 0.01\% Trolox.

\section{Characteristics of FWB}

As shown in Table 2, the protein, carbohydrate, and fat of FWB were 9.0, 11.5 , and $0.2 \%$, respectively. The protein content of FWB showed almost twice higher than that of commercial yogurt products, and was similar with that in commercial protein drinks or shakes. Regarding viscosity, fermentation by lactic acid bacteria caused increasing viscosity of the FWB produced. According to Hassan et al. (2012), the viscosity behavior is related to the $\mathrm{pH}$, so the increase in viscosity takes place at acidic value.

One of the characteristic features of fermentation by lactic acid bacteria is the production of different organic acids, due to the degradation of some components in the raw material, and the resultant decrease in $\mathrm{pH}$ (Wu et al., 2011). Therefore, the organic acid profile in fermented

Table 2. Antimicrobial activity of fermented whey beverage

\begin{tabular}{ccccc}
\hline \hline \multirow{2}{*}{ Test microorganisms } & \multicolumn{3}{c}{ Clear zone (mm) } \\
\cline { 2 - 5 } & NFWB & FWB & FWB-LH 166 & FWB-ST Body1 \\
\hline Stapylococcus aureus & 0 & $11 \pm 0.5$ & $11 \pm 0.1$ & $12 \pm 0.3$ \\
Salmonella enterica & 0 & $10.5 \pm 0.5$ & $10 \pm 0.5$ & $9.5 \pm 0.2$ \\
\hline
\end{tabular}

NFWB, non-fermented whey beverage; FWB, whey fermented beverage with mix culture (Lactobacillus plantarum DK 211+ Lactococcus lactis R704); FWB-LH 166, whey fermented beverage with Lactobacillus helveticus LH 166; FWB-ST Body1, whey fermented beverage with Streptococcus thermophilus ST-Body1.

All values are mean $\pm \mathrm{SD}$ of triplicates. 
dairy foods is an indicator of the metabolic activity of added bacterial cultures. These acids act as natural preservatives, and contribute to the characteristic sensory properties (Adhikari et al., 2002). Lactic acid contents greatly increased as much as 3.5 times during fermentation, while there was less increase in the content of citric acid. These results were similar with those of Adhikari et al. (2002), in which there was a 3-fold increase in the content of lactic acid during fermentation. However, in their study, the unfermented mix had a higher amount of citric acid than the fermented product. They explicated that it was because of the utilization of citric acid by the yogurt starter during fermentation.

FWB sample stored at $4^{\circ} \mathrm{C}$ had slight acid development during the storage period, while the samples stored at 10 and $15^{\circ} \mathrm{C}$ showed post-fermentation acidification, as the $\mathrm{pH}$ decreased from 4.5, to around 3.7 at $28 \mathrm{~d}$ of storage (Fig. 4). A similar behavior was suggested by Almeida et al. (2009), who observed that the post-acidification behavior of most co-cultures was faster in a milk-whey base.

To exert beneficial health effects, the amount of probiotic bacteria in the food product should be adequately high, i.e., $10^{6}-10^{8} \mathrm{CFU} / \mathrm{mL}$ throughout the entire shelf life (Najgebauer-Lejk, 2014). Table 3 shows that the level of probiotics in this study maintained $10^{9} \mathrm{CFU} / \mathrm{mL}$ during $28 \mathrm{~d}$ of the storage period, regardless of the storage temperature, which was beyond this criterion.

\section{Functional properties of FWB}

Antioxidant activity has been reported for milk proteins, sodium caseinate and whey protein concentrate, yoghurt, and lactic acid bacteria (Unal and Akalm, 2012). Two antioxidant assays were employed to measure the antioxidant activity of FWB, i.e., DPPH and FRAP assay. DPPH assay is used to evaluate the ability of antioxidant to scavenge free radicals, which is known to give reliable information concerning the antioxidant ability of the tested compounds (Zha et al., 2009). Transition metal ions are also involved in many oxidation reactions in vivo, as the reduced form of iron causes oxygen toxicity, by converting the less reactive hydrogen peroxide to the more

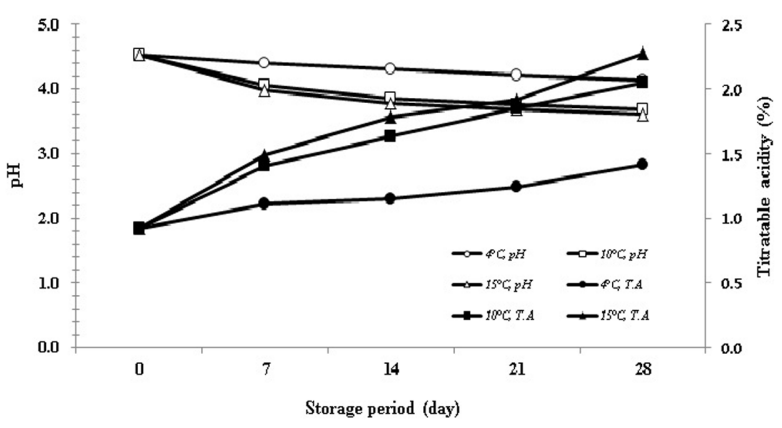

Fig. 5. Changes in $\mathrm{pH}$ and titratable acidity of whey fermented beverage during storage.

reactive oxygen species, such as hydroxyl radical, via the Fenton reaction (Unal and AKalm, 2012; Zha et al., 2009). The FRAP assay measures the reduction of ferric to ferrous ion at low $\mathrm{pH}$ in the presence of antioxidants, which causes a colored ferrous-tripyridyltriazine complex to form (Gliszczynska-Swiglo, 2006).

To ensure that the measured antioxidant activity was produced during fermentation, the antioxidant activity of non-fermented whey beverage was measured. The DPPH scavenging activity of samples ranged from $10.2 \%$ (nonfermented sample) to $42.07 \%$, when Trolox at a concentration of $0.1 \mathrm{mg} / \mathrm{mL}$ showed a DPPH scavenging activity of $68.93 \%$ (Fig. 5A). Regardless of the starter culture, all fermented whey beverage samples had a higher DPPH scavenging activity than the non-fermented one, indicating that fermentation by lactic acid bacteria increased antioxidant levels. FRAP values in all fermented products were also 3 times higher than in the non-fermented one (Fig. 5B). Increased scavenging effect of FWB might be due to antioxidant peptides released during the fermentation of milk by lactic acid bacteria.

Unal and Akalm (2012) who studied the antioxidant activity of yoghurt fortified with different types of milk protein, revealed that whey protein concentrate showed higher scavenging activity than sodium calcium caseinate. They stated that high scavenging activity of the whey proteins could be attributed to lactoferrin, $\alpha$-lactalbumin, and $\beta$-lactoglobulin. Species of Lactobacillus being widely

Table 3. Changes in viable cell counts of fermented whey beverage during storage

\begin{tabular}{ccccc}
\hline \hline Storage temp. $\left({ }^{\circ} \mathrm{C}\right)$ & \multicolumn{4}{c}{ Viable cell counts (Log CFU/mL) } \\
\cline { 2 - 5 } & $0 \mathrm{~d}$ & $7 \mathrm{~d}$ & $9.57 \pm 0.10$ & $28 \mathrm{~d}$ \\
\hline 4 & $9.62 \pm 0.05$ & $9.60 \pm 0.03$ & $9.59 \pm 0.09$ \\
10 & $9.67 \pm 0.06$ & $9.41 \pm 0.11$ & $9.48 \pm 0.04$ & $9.49 \pm 0.05$ \\
15 & $9.60 \pm 0.08$ & $9.46 \pm 0.10$ & $9.60 \pm 0.05$ & $9.45 \pm 0.10$ \\
\hline
\end{tabular}

All values are mean $\pm \mathrm{SD}$ of triplicates. 
used as starter cultures in the dairy industry have been reported to play a significant role in the production of bioactive peptides in fermented dairy products (Ramesh et al., 2012). Farvin et al. (2010) also indicated that the milk peptides act as electron donors, and could react with free radicals, to convert them to more stable products. The strong proteolytic activity of L. plantarum DK 211 was already observed in Fig. 1. Therefore, the antioxidant activity of FWB fermented with the mixture culture of $L$. plantarum DK 211 and Lactococcus lactis could be due to the peptides produced by the action of L. plantarum DK 211.

The antibacterial activity of FWB prepared with selected strains was estimated by the agar diffusion method. A strong inhibitory effect of FWB on the growth of Stapylococcus aureus and Salmonella enteritica was detected (Table 4). It has recently been reported that Lactobacillus sp. strains inhibit the growth of Gram-negative pathogenic bacteria, which has generally been attributed to the production of lactic acid during the Lactobacillus growth (Nikolova et al., 2009).

\section{Sensory evaluation}

By the addition of a high amount of whey protein, FWB had higher protein content as much as twice, and significantly lower fat content, than the commercial product. However, FWB had a low acceptability score, because of the unappealing taste and excessive acidity of whey protein, which consequently affects the overall taste of the product in preliminary study (data not shown). Djurić et al. (2004) also stated that numerous procedures have been developed for characteristics of whey protein. This defect can be overcome by adding flavor components, such as vanilla or fruit flavor. Vanilla flavor was selected to add to the final product, because this flavor was found through the preliminary sensory test to be better matched with FWB than fruit flavors, such as banana and strawberry (data not shown).

Table 5 shows the mean panelists rating of the sensory attributes of the FWB and control. There were no significant differences in the ratings of all attributes, except sourness. The FWB was found to contain sour characteristics, which seemed highly correlated with the lactic acid content. The stinky smell of whey protein in FWB seems to have been improved by the addition of vanilla flavor, because there were no significant differences in the ratings of aftertaste and off-flavor with the commercial product. Sensory evaluation of FWB showed that it was a favorable product, as the panelist ratings for overall taste
Table 4. The chemical composition and physical property of non-fermented whey beverage (NFWB), fermented whey beverage (FWB) and commercial product (control)

\begin{tabular}{cccc}
\hline \hline & NFWB & FWB & Control \\
\hline Protein (\%) & ND & 9.0 & 4.5 \\
Carbohydrate (\%) & ND & 11.5 & 9.0 \\
Fat (\%) & ND & 0.2 & 3.0 \\
Lactic acid (mg/mL) & 1.44 & 5.04 & 1.70 \\
Citric acid (mg/mL) & 0.48 & 1.44 & 1.41 \\
Viscosity (cp) & $7.20 \pm 0.1$ & $33.6 \pm 0.1$ & $9.6 \pm 0.2$ \\
\hline
\end{tabular}

ND, not detected.

The values for organic acid contents and viscosity are mean $\pm \mathrm{SD}$ of triplicates.

Table 5. Mean panelist ratings for FWB and commercial product (control)

\begin{tabular}{ccc}
\hline \hline \multirow{2}{*}{ Parameters } & \multicolumn{2}{c}{ Samples } \\
\cline { 2 - 3 } & FWB & Control \\
\hline Overall taste & $4.92^{\mathrm{a}}$ & $5.03^{\mathrm{a}}$ \\
Flavor & $5.50^{\mathrm{a}}$ & $5.16^{\mathrm{a}}$ \\
Freshness & $4.66^{\mathrm{a}}$ & $4.80^{\mathrm{a}}$ \\
Aftertaste & $4.83^{\mathrm{a}}$ & $4.93^{\mathrm{a}}$ \\
Off-flavor & $4.33^{\mathrm{a}}$ & $4.30^{\mathrm{a}}$ \\
Sourness & $4.14^{\mathrm{a}}$ & $2.83^{\mathrm{b}}$ \\
Sweetness & $3.80^{\mathrm{a}}$ & $3.77^{\mathrm{a}}$ \\
\hline
\end{tabular}

$\overline{\text { FWB, Fermented whey beverage; control, a commercial brand, a }}$ banana flavored processed milk fortified with milk protein concentrate.

${ }^{\mathrm{a}, \mathrm{b}}$ means with different letters are significantly different $(p<0.05)$.

and aftertaste were above the mid-point.

The results obtained in this study provide evidence that a novel high-protein beverage having functional properties and acceptable organoleptic character could be produced by fermentation of whey protein using L. plantarum DK 211, a vegetable-origin lactic acid bacterium.

\section{Acknowledgements}

The present research was conducted by the research fund of Dankook University in 2014.

\section{References}

1. Adhikari, K., Grûn, I. U., Mustapha, A., and Fernando, L. N. (2002) Changes in the profile of organic acids in plain set and stirred yogurts during manufacture and refrigerated storage. J. Food Qual. 25, 435-451.

2. Almeida, K. E., Tamime, A. Y., and Oliveira, M. N. (2009) Influence of total solids contents of milk whey on the acidifying profile and viability of various lactic acid bacteria. $L W T$ Food Sci. Technol. 42, 672-678.

3. Athanasiadis, I., Paraskevopoulou, A., Blekas, G., and Koss- 
eoglou, V. (2004) Development of a novel whey beverage by fermentation with kefir granules-Effect of various treatments. Biotechnol. Prog. 20, 1091-1095.

4. Beganović, J., Kos, B., Pavunc, A. L., Uroić, K., Džidara, P., and Šušković, J. (2013) Proteolytic activity of probiotic strain Lactobacillus helveticus M92. Anaerobe 20, 58-64.

5. Campagne, C. P., Tompkins, T. A., Buckley, N. D., and GreenJohnson, J. M. (2010) Effect of fermentation by pure and mixed cultures of Streptococcus thermophiles and Lactobacillus helveticus on isoflavone and B-vitamin content of a fermented soy beverage. Food Microbiol. 27, 968-972.

6. Cho, Y. H., Hong, S. M., and Kim, C. H. (2013) Isolation and characterization of lactic acid bacteria from kimchi, Korean traditional fermented food to apply into fermented dairy products. Kor. J. Food Sci. An. 33, 75-82.

7. Djurić, M., Carić, M., Milanović, S., Tekić, M., and Panić, M. (2004) Development of whey-based beverages. Eur. Food Res. Technol. 219, 321-328.

8. Farvin, K. S., Baron, C. P, Nielsen, N. S., and Jacobsen, C. (2010) Antioxidant activity of yoghurt peptides: Part 1-in vitro assays and evaluation in $\omega-3$ enriched milk. Food Chem. 123, 1081-1089.

9. Gliszczynska-Swiglo, A. (2006) Antioxidant activity of water soluble vitamins in the TEAC (Trolox equivalent antioxidant capacity) and the FRAP (ferric reducing antioxidant power) assays. Food Chem. 96, 131-136.

10. Hassan, A. A., Aly, M. M. A., and El-Hadidie, S. T. (2012) Production of cereal-based probiotic beverages. World Appl. Sci. J. 19, 1367-1380.

11. Hugunin, A. (2008) US whey ingredients in yogurt and yogurt beverages. US Dairy Export Council. Available from: http://usdec.files.cms-plus.com/PDFs/2008Monographs/Yog urtMonograph2009.pdf

12. Khalid, N. M. and Marth, E. H. (1990) Proteolytic activity by strains of Lactobacillus plantarum and Lactobacillus casei. J. Dairy Sci. 73, 3068-3076.

13. Khalid, K., Kiong, L. H., Chowdhury, Z. Z., and Khalid, K. (2011) Antimicrobial interaction of Lactococcus lactis subsp. lactis against some pathogenic bacteria. Int. J. Biosci. 1, 3944.

14. Ko, I. H., Wang, M. K., Jeong, B. J. and Kwak, H. S. (2005) Fermentation for liquid-type yogurt with Lactobacillus casei 911LC. Asian Australas. J. Anim. Sci. 18, 102-106.

15. Korhonen, H. (2009) Milk-derived bioactive peptides: From science to applications. J. Funct. foods 1, 177-187.

16. Lee, H., Yoon, H., Ji, Y., Kim, H., Park, H., Lee, J., Shin, H., and Holzapfel, W. (2011) Functional properties of Lactobacillus strains isolated from kimchi. Int. J. Food Microbiol. 145, 155-161.

17. Lim, S. M. and Im, D. S. (2009) Screening and characterization of probiotic lactic acid bacteria isolated from Korean fermented foods. J. Microbiol. Biotechnol. 19, 178-186.

18. Najgebauer-Lejko, D. (2014) Effect of green tea supplementation on the microbiological, antioxidant, and sensory properties of probiotic milks. Dairy Sci. Technol. 94, 327-339.

19. Nikolova, D., Petrova, M., Evstatieva, Y., Danova, S., and Atev A. (2009) Antimicrobial activity of Lactobacillus helveticus strain 50P1. Trakia J. Sci. 7, 40-44.

20. Pescuma, M., Hébert, E. M., Mozzi, F., and Font de Valdez, G. (2010) Functional fermented whey-beverage using lactic acid bacteria. Int. J. Food Microbiol. 141, 73-81.

21. Ramesh, V., Kumar, R., Singh, R. R. B., Kaushik, J. K., and Mann, B. (2012) Comparative evaluation of selected strains of lactobacilli for the development of antioxidant activity in milk. Dairy Sci. Technol. 92, 179-188.

22. Rathore, S., Salmerón, I., and Pandiella, S. S. (2012) Production of potentially probiotic beverages using single and mixed cereal substrates fermented with lactic acid bacteria cultures. Food Micorbiol. 30, 239-244.

23. Rittmanic, S. (2008) U.S. whey proteins in ready-to-drink beverages. US Dairy Export Council. Available from: http:// usdec.files.cms-plus.com/PDFs/2008Monographs/WheyRea dDrinkBeverages_English.pdf

24. Shiby, V. K., Radhakrishna, K., and Bawa, A. S. (2013) Development of whey-fruit-based energy drink mixes using Doptimal mixture design. Int. J. Food Sci. Technol. 48, 742748.

25. Sinha, R., Radha, C., Prakash, J., and Kaul, P. (2007) Whey protein hydrolysate: Functional properties, nutritional quality and utilization in beverage formulation. Food Chem. 101, 1484-1491.

26. Unal, G. and Akalm, A. S. (2012) Antioxidant and angiotensinconverting enzyme inhibitory activity of yoghurt fortified with sodium calcium caseinate or whey protein concentrate. Dairy Sci. Technol. 92, 627-639.

27. Vijayaraghavan, P. and Vincent, S. G. P. (2013) A simple method for the detection of protease activity on agar plates using bromocresolgreen dye. J. Biochem. Tech. 4, 628-630.

28. Walsh, H., Ross, J., Hendricks, G., and Guo, M. (2010) Physico-chemical properties, probiotic survivability, microstructure, and acceptability of a yogurt-like symbiotic oats-based product using pre-polymerized whey protein as a gelation agent. J. Food Sci. 75, M327-M337.

29. Wu, S. C., Su, Y. S., and Cheng, H. Y. (2011) Antioxidant properties of Lactobacillus-fermented and non-fermented Graptopetalum paraguayense E. Walther at different stages of maturity. Food Chem. 129, 804-809.

30. Zha, X. Q., Luo, J. P., Zhang, L., and Hao, J. (2009) Antioxidant properties of different polysaccharides extracted with water and sodium hydroxide from rice bran. Food Sci. Biotechnol. 18, 449-455. 